there were as many as 322, while the aggregate of individuals dying in Rome, but belonging to other parts of Italy and to foreign countries, was 836 for eleven months of the year. *After the subtraction of those deaths, the total mortality for the year was 9,144 , or 37.4 per 1,000 living. The high death-rate among those not belonging to the community requires some explanation, and seems partly due to the fact of Rome having been overcrowded with the poorest of the labouring classes from all parts of the kingdom, who anticipated obtaining employment on the numerous public works which have been begun since the city came into possession of the Italians, and who, on account of the greatly enhanced prices of food and lodging, have been most wretchedly fed, and have been obliged to live in underground cellars without light or air in the colder season, while in the hotter months their sole sleeping quarters were too often the porticoes of the churches and public buildings. Among those unfortunate people the mortality has been appalling, and, as most of them came from parts of Italy where there was no ague, it has been greatly owing to pernicious intermittent fever. In addition, it is probable that the hospitals of Rome have attracted to them the invalids from a wider district of country than they used to do, as almost all the deaths of those not belonging to the community took place in the hospitals, only 90 out of 836 having died elsewhere in the city; figures which by themselves go far to prove that foreign residents and visitors suffered but little from the prevalent unhealthiness of the year. During the four months, July, August, September, and October, there were admitted I1,000 patients into one hospital, the Santo Spirito, or nearly as many as are usually received throughout the whole year. In the medical hospitals, with the exception of one or two wards used for clinical purposes, there is no part of the various buildings which even partially answers to the requirements of modern hospital construction, and with any great influx of patients the overcrowding must prove most deadly. The surgical hospitals are better constructed, but they, too, are overflowing with patients, and, indeed, rather more than one death out of every three-and-a-half deaths in 1872 took place in the hospitals.

In endeavouring to explain the high death-rate of the past twelve months in Rome, we find that in the first quarter the increased mortality was greatly owing to an epidemic of small-pox which, beginning in the October of $187 \mathrm{I}$, gradually increased in severity until about the end of the third week in January, 1872, when it attained its maximum. Between the Ioth of October, $187 \mathrm{r}$, and the 4 th of February, 1872, the epidemic caused no fewer than 544 deaths, 209 of which are included in the death returns of 1872 . From the middle of February the epidemic began to abate, and by the middle of August the deaths from this cause had fallen to an average of 7 per week. Still, the slaughter caused by small-pox has been truly startling, 737 persons having lost their lives in one year from this the most preventable of zymotic diseases. That a large number of those deaths must be ascribed to the want of vaccination, or to its careless and inefficient performance, may be concluded from the returns, which prove that 67.6 per cent. of all the deaths from small-pox were those of children under five years of age, many of which a compulsory Vaccination Act would have prevented. That this deduction is justifiable is evident from the fact that when we find small-pox occurring epidemically in a tolerably well raccinated community, such as that of Scotland, the mortality caused by it among children under five years of age does not attain twenty-five per cent., $t$ or less than one-fourth of all the deaths from small-pox occur at ages under five years, instead of over two-thirds, as in this last epidemic at Rome. In other words, had the population of Rome been even as well vaccinated as that of the larger towns in Scotland, it is probable that the lives of more than two hundred children would have been saved.

Small-pox, however, was unfortunately not the only zymotic disease which raged in the city throughout nearly the whole of 1872 . Diphtheria and croup-combined in the Registrar's reports-were terribly prevalent, and occasioned, in the fifty-two weeks ending December 29th, 571 deaths. Here, too, the proportion of children under five years of age who fell victims was enormous, being 78.8 per cent. of the total deaths from those two complaints. Typhoid fever is entered as the cause of 354 deaths, and pernicious intermittents killed 417 persons. Measles, too, seems to have assumed a destructive type, a 166 deaths are registered from it, only 20 being given as those of persons over five years of age. Scarlatina, on the other hand, was mild, and caused only 25 deaths; nor does any other complaint call for particular notice, except pyæmia, which also figures prominently in the returns. Summing up the deaths from these seven zymotic complaints

\footnotetext{
The returns for January do not discriminate between deaths belonging and not belonging to the community; and there is, consequently, a slight error in the way of excess in the estimated mortality of the year.

+ See Seventeenth Annual Report of the Registrar-General for Scotland, p. 39.
}

-rmall-pox, diphtheria, croup, scarlatina, typhoid fever, measles, and pernicious intermittents - we find that they number 2,270 , or consider. ably more than one-fifth of the total mortality of the year.

The fatality of this class of diseases was, however, by no means uni. formly distributed over the whole twelve months, as may be shown by the accompanying table. Scarlatina has been omitted, on account of its being, fortunately, too insignificant an item in the returns; and owing to the form of the reports, it has been necessary to draw up the table in periods of twelve weeks. The four weeks omitted, from June I th to July I $4^{\text {th, }}$ present no special features, the mortality from all the complaints mentioned being intermediate between the four pre. ceding and the four succeeding weeks.

\begin{tabular}{|c|c|c|c|c|c|}
\hline \multirow{2}{*}{ Year 1872.} & \multicolumn{5}{|c|}{ Deaths. } \\
\hline & Smallpox. & $\begin{array}{l}\text { Diphtheria } \\
\text { and Croup. }\end{array}$ & $\begin{array}{c}\text { Pernicious } \\
\text { Intermittents. }\end{array}$ & $\begin{array}{c}\text { Typhoid } \\
\text { Fever. }\end{array}$ & Measles. \\
\hline $\begin{array}{l}\text { From Jan. I to } \\
\text { March } 24 \\
\text { From March } 25\end{array}$ & 392 & 142 & 52 & 84 & 3 \\
\hline $\begin{array}{l}\text { to June } 16 . \\
\text { From July } 15\end{array}$ & 166 & 284 & 39 & 53 & $x_{4}$ \\
\hline $\begin{array}{l}\text { to Oct. } 6 \ldots . . . \\
\text { From Oct } 7 \text { to }\end{array}$ & 75 & rro & 199 & 105 & $x 07$ \\
\hline Dec. $29 \ldots$ & $7 \mathrm{I}$ & 93 & 109 & 84 & 26 \\
\hline
\end{tabular}

This table, though presenting a very high bill of mortality, is so far consolatory that there is a manifest improvement in the last twelve weeks of 1872 -an improvement which we may expect to continue in the present year, as the epidemic of small-pox is now virtually at an end ; no deaths from this cause having been registered in the third week of January, while only seven cases of discrete and semi-confluent variola remained in the small-pox wards when I last visited them; and the other zymotic complaints, too, show a notable diminution in the first four weeks of 1873 .

[To be continued.]

\section{THE ETIOLOGY OF PSORIASIS.}

\section{BY BALMANNO SQUIRE, M.B.Lond.}

As Dr. Myrtle has done me the compliment of commenting on my remarks on the etiology of psoriasis, and has expressed himself as arriving at a somewhat different conclusion -from mine, I beg the privilege of a reply. He does not agree with me that psoriasis was the disease of the "leper as white as snow" of the Bible, and he objects because " the word 'white' does not occur in the original, and is never used by eastern nations as it is by us," although later on he says that " the word 'white' is applied [in the Bible] to the hair and spots of the leper." Now, if I waive this apparent contradiction, and assume with him that the original words stand simply "a leper as snow," am I to understand him as saying that they imply no reference to the whiteness of the leper, and, if so, that they refer to a question of tem. perature, or of purity, or of what ? and (if the word white is never used by eastern nations as it is by us) will he explain in what sense they do use it? The learned individuals who translated the Bible into English, at least, were of opinion that a "leper as snow" (if that be the original) meant a leper as white as snow ; for so they have rendered it.

Dr. Myrtle objects to the identity I have sought to establish between the ancient and the modern disease, that the former, in the instances quoted, "was not disease in the ordinary or natural course, but instances of miraculous interference with healthy skins." But, if it be not profane to think that the constant maintenance of the varied but undeviating laws of nature is a greater miracle than any conceivable devia. tion from them, this argument will not go for much. I am sure of this, that a strong mental emotion is well capable of determining a general eruption of psoriasis ; for such cases have repeatedly come under my notice, and I can conceive no stronger exciting cause of the disease than a solemn curse pronounced by the lips of a person to whom the patient unreservedly imputed supernatural power. To take a case where mental emotion is generally allowed to have a considerable influence, I think I may safely say that most pregnant women would be likely to abort under the circumstances.

Dr. Myrtle then goes on to say that, although there can be no doubt as to psoriasis being hereditary, nevertheless race, so far as he has been

* According to Professor Baccelli, in his pamphlet on La Perniciosita, the maximum number of pernicious intermittents in Rome occurs in the months of July, August, September, and October ; the medium in June, November, December, and January ; and the minimum in February, March, April, and May. 
able to ascertain, has nothing to do with it. Now, this is scarcely enough to refute a more definitely assumed position. He does not even as much as say that he has ever made any careful attempt to ascertain whether race has anything to do with it or not; that he has, in fact, even voluntarily put himself into any other attitude of mind than that of assuming that race cannot have anything to do with it. Still less does he make any reference as to investigations respecting the particular race I speak of.

My interpretation of the biblical phrase was based chiefly on the frequency of psoriasis as computed by myself amongst my Jewish acquaintances and patients, and only secondarily on the patness of that phrase as a pathognomonic description of the disease; but Dr. Myrtle, in disposing of my dogma, does not think it essential to say that any Hebrew patient affected with skin-disease has ever come under his notice. It is a prima facie inconsistent, although not quite a contradictory, statement to say, as he does, of a disease which is confessedly hereditary that it cannot be an affair of race. But, to comment on my commentator, who will agree with Dr. Myrtle in saying that, although those whom this disease more particularly attacks " are especially the blooming and healthy," yet "its depressing effect on the spirits is so great and constant" that the female, at least, "soon grows melancholy, and ere long falls a victim to decline?" and who, after joining him in saying "I have been struck with the number of cases where the disease is confined entirely to parts of the body which are always under cover," will then (speaking in general terms of the female subject of it) say "she cannot go into society and dress like other girls?" If evening toilette be referred to, it is inaccurate to impute to psoriasis a general tendency to affect the upper part of the back or the neck and shoulders, and, even if it were so, the remark is hardly a relevant one, now that high square-cut bodies with sleeves to the elbow are de rigucur for evening dress. But Dr. Myrtle goes farther, he says "she may be admired, have offers of marriage, but all is a mockery." I sincerely hope it has not come to that.

Is Dr. Myrtle unaware that a great many married ladies have psoriasis, and, more than that, had it at the time they were wooed and won? or does he think that "blooming healthy individuals" are at such a discount, even with the drawback (if it be one) of a patch or two of psoriasis? I wish I could say, with Dr. Myrtle, that, as a general result, the effect of the Harrogate waters on psoriasis contrasts most favourably with that obtained from all other methods of cure previously adopted ; if so, I could find a short cut out of many an occasional diffi culty. But I have met with too many persons with psoriasis who had "steadily persevered" with the IIarrogate waters "for months."

\section{THE LEPROSY OF THE BIBLE.}

\section{BY A. DUNBAR WALKER, M.D.}

THE leprosy of the Bible has always been a vexed question, and in the present day seems no nearer solution than before. That the "creatures" (for really persons without hands and feet, wanting the greater part of the nose, with voices reduced to little else than a croak, and whose existence is a burden to themselves and their friends, are little above creatures) who meet one at the gates of a Syrian town in the present day are the lepers of Scripture, is generally disallowed; for the disease is not contagious, commences quite differently, and produces a disease in no particular resembling that recorded in Leviticus. Ele phantiasis Græcorum, also, as seen in the East, is hereditary, which is not recorded about leprosy of old. Dr. Hebra, in a note to his article on scabies, in his comprehensive and learned work on skin-diseases, has suggested that scabies was the leprosy of the Israelites, adducing in its favour- $\mathbf{I}$, the contagious character of the disease ; 2 , the cure employed in Naaman's case-washing in the Jordan, a river whose water contains sulphur. In analysis of Jordan water sulphur is found, but certainly not in sufficient quantity to remove scabies by " washing seven times". The amount of sulphur in solution varies according to the place from which the water is taken : if near the source, it is in small quantities; and there is no doubt that it was near the commencement of the river that Naaman washed, for it is this part that lies on the road to Damascus. The most convincing circumstance, to my mind, that scabies was not the disease, is its rarity in Syria in the present day. In a year's experience of all kinds of diseases in Syria, amongst which were many cases of skin-diseases, no case of scabies presented itself to my notice.

Mr. Balmanno Squire has put forth in the Journal the idea entertained by many, that psoriasis presents many of the features recorded in Scripture regarding leprosy, supporting his theory by its frequency amongst English Jews and Asiatics. Of the greater frequency of psoriasis amongst Orientals, and more especially amongst Syrians, my ex- perience in Syria is quite confirmatory ; for amongst the Arabs I saw many cases, and more in proportion to the number of inhabitants than in England. But at the same time, of northern and western nations, removed far from Asiatic influence or blood, Norway affords as many cases of psoriasis, in proportion to its inhabitants, as Syria; and we find in this country elephantiasis Græcorum cropping up. Psoriasis is also a non-infectious disease, which was a character that pre-eminently distinguished the ancient leprosy. My own comparison of the Scriptural disease, with diseases now known in Syria or any other country, has brought me to think that the leprosy of the Israelites has entirely disappeared ; and that, when in existence, it depended on some fungus which attached itself to the hairs of man and animals, producing a crust similar to favus, only of a white colour, for we find it producing its effects not only on men, but on the skins of animals worn as garments, and on the walls of the houses.

As to the treatment of psoriasis, Dr. Myrtle's remarks are very sensible : that there is no specific in arsenic, cod-liver oil, or any other individual medicine, I quite agree with him. As the patients that labour under the disease are so different in age and constitution, so must our remedies vary; and if one remedy fail, another must be tried. The most potent remedies being, no doubt, change of air and diet, unfortunately the disease is apt to recur, after the patient has resumed for some time his former habits and abode. In a case which I had under my care, a sea-voyage acted beneficially by dispersing the disease, but it returned after two years.

\section{NOTES ON BOOKS.}

A very useful little Medical and Surgical Handhook for thi Guidance of Officers in command of those Vessels in II.M. Sirvice in which no Medical Officer is borne, has been issued by the Admiralty. It is very concise, dwelling practically on hygienic measures, as cleanliness, ventilation, sleeping arrangements, clothing, food and water, sun-exposure, and endemic morbific influences; it then scans briefly, in alphabetical order, the common disorders and accidents to which seamen are liable, giving good modes of treatment easily applicable to them. In many respects it resembles the similar brochures that have been so well prepared as guides to merchant captains by Spencer IVells and by Harry Leach, excelling them in the style of the pictorial illustrations of surgical accidents, and in the manner in which cases of suspended anima. tion by drowning should be dealt with on the directions of the Royal Humane Society. We recommend it as well adapted to its purpose, and likely to be very useful, as such lessons cannot be too strongly impressed on all executive officers, especially as they are often on detached service in boats, without any medical officer at hand. We believe it is the intention of the Admiralty to institute a series of lectures on this important branch of nautical education at the new Naval College, Greenwich.

The Student's Handbook of the Practice of Medicini, by II. AUBREy HUSBAND, M.B. (Edinburgh, E. and S. Livingstone), is by far too meagre for an useful purpose; and we think it really impossible that any student preparing for examination can be so ill-informed as to benefit by reading it. It savours of the absurd attempt to compress the whole practice of medicine into a brochure that can be carried in the waistcoat-pocket.

Syphilis, its Nature and Treatment: with a Chaficr on Gonorrhat. By C. A. Drysdale, M.D. Second Edition. London: Ballière, Tindall, and Co.-Dr. Drysdale must be counted amongst the honest doubters. Ife draws a very heavy indictment against the use of mercury in the treatment of syphilis; and, although this is amongst the heresies of modern times, it is one which deserves attention. This disbelief in the value of mercury as an antisyphilitic may be only an excessive reaction of opinion against the undoubted abuses which have been, and the exaggerated faiih which still is, allied with its use. The results of the study of the natural history of syphilitic iritis by J. Z. Laurence, Gascoyen, and Hart, alone suffice to show that its value is certainly over-estimated by the majority of ophthalmic practitioners and no better field of observation could be selected as a testing-ground than iritis and irido-choroiditis, where the processes of deposition and absorption of lymph may be watched with the naked eye and with the ophthalmoscope. It has been sufficiently ascertained that reabsorption will go on very actively without the intervention of mercurial treatment and it may be doubted whether the influence of mercury really hastens the process. Dr. Drysdale's book is somewhat confused and ill-arranged, and he does not possess sufficiently the faculty of assorting his collections of observations and opinions, and balancing them; but, as a small magazine of collected statements on the important subjects which it treats, it has much interest and value. 